\title{
Hydrogeochemical survey of the Bagni di Lucca thermal zone with the purpose of monitoring hydrogeochemical foresights of earthquakes (Northern Tuscany, Italy)
}

\author{
Lisa Pierotti ${ }^{1,}$, Daniela Andreani ${ }^{1}$, Flavia Botti $^{2}$, Matteo Chiellini ${ }^{2}$ \\ ${ }^{1}$ Consiglio Nazionale delle Ricerche (CNR), Istituto di Geoscienze e Georisorse (IGG), via \\ G.Moruzzi 1, Pisa 56124, Italy \\ ${ }^{2}$ Università di Pisa, Dipartimento di Scienze della Terra (DST), via Santa Maria 53, Pisa 56126, Italy
}

\begin{abstract}
We present the results of a hydrogeochemical survey of the Bagni di Lucca area, a thermal district in the Serchio Valley, one of the areas of highest seismic risk in Tuscany, Italy. The aim of the survey was to identify a suitable site to be monitored for geochemical precursors of earthquakes. Based on hydrogeological and geochemical features, the Bernabò spring emerged as a proper candidate site for the installation and testing of an automatic monitoring station equipped with specific sensors for the continuous measurement of selected physical-chemical parameters (temperature, $\mathrm{pH}$, electrical conductivity, redox potential).
\end{abstract}

\section{Introduction}

As a part of a project funded by the Government of the Tuscany region to study earthquake precursors [1], detailed hydrogeochemical surveys were carried out in the Serchio and Magra valleys, Northern Tuscany, to identify suitable sites where to install water continuous automatic monitoring stations [2,3]. In order to study the chemical variations possibly related to the deep processes in the preparatory phases of the seismic events [e.g. 4], springs/wells discharging fluids representative of deep-seated circuits were selected in correspondence to the main neotectonic structures of the region. In this manuscript, we present the results of the hydrogeochemical survey carried out in the Bagni di Lucca area, a thermal district in the Serchio valley where more than 40 thermal and cold springs emerge in a restricted area of about $3 \mathrm{~km}^{2}$. Some of the thermal springs are currently exploited for bathing and balneotherapy. The present study was done in two main steps. The first step consisted in identifying the Bernabò spring $\left(\mathrm{T} \sim 41.2{ }^{\circ} \mathrm{C}\right)$ as the "most suitable" monitoring point among the 41 springs surveyed. This spring was selected as the most representative of the local deep hydrothermal circuits, being scarcely affected by mixing processes with shallow groundwater of meteoric origin. The second step consisted in defining the geochemical background of the Bernabò spring by combining data from discrete sampling/analysis (major dissolved constituents) and from the continuous

*Corresponding author: 1.pierotti@igg.cnr.it 
monitoring of selected physical-chemical parameters (temperature, $\mathrm{pH}$, electrical conductivity and redox potential). Periodic water sampling was done on a monthly basis, whereas the continuous monitoring was carried out every two minutes by an automated station equipped with parameter-specific sensors, to detect even signal variations occurring over very short time intervals.

\section{Geological and hydrogeological setting}

The Serchio Valley belongs to the inner part of Northern Apennines, a fold-and-thrust belt of geological units of oceanic and continental origin [5]. The uppermost units of the tectonic pile (Ligurian Units and Tuscan Units) show both contractional as well as syn-to late-orogenic extensional features. Low-angle and high-angle normal faults of Tortonian to Quaternary age confer a 'semi-graben' type geometry on Serchio intermountain basins. Vertical movements of $\sim 4 \mathrm{~km}$ of the underlying Tuscan Metamorphic Unit [6] are associated with these structures.

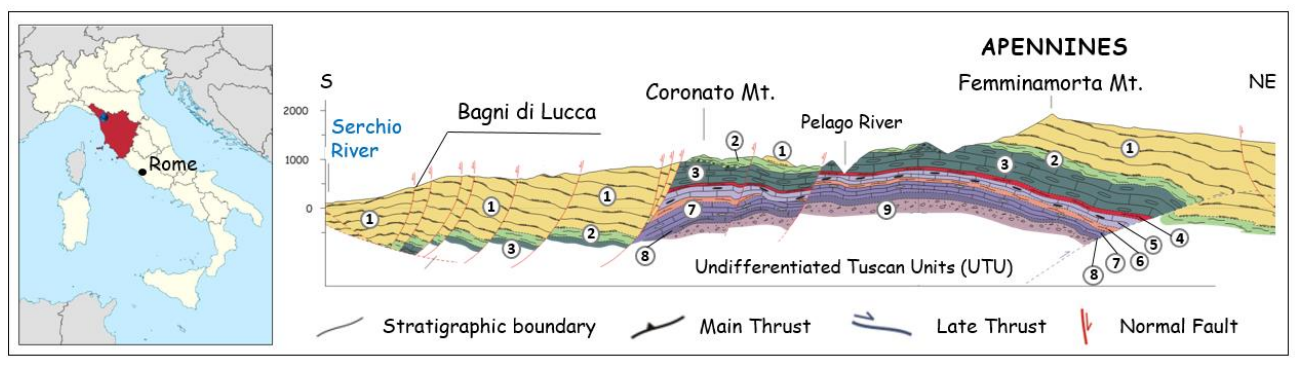

Fig. 1. Geological-structural cross-section showing the deformation styles and tectonic setting of the Serchio Valley. Legend: 1 - Macigno flysch; 2 - Scaglia shales; 3 - Maiolica limestone; 4 - Diaspri cherts; 5 - Lima Valley cherty limestone; 6 - Posidonia marls; 7 - Limano cherty limestone; 8 - Massif limestone; 9 - Vugular limestones and evaporites.

The carbonate outcrops of Coronato Mount, in the Lima Valley, and of Corfino and Soraggio, on Apennines (Fig. 1), are considered as the main recharge areas of the regional hydrothermal circuit [3]. Meteoric water is also supposed to infiltrate locally through cataclastic layers affecting the impermeable cover, allowing for a secondary recharge of the deep reservoir via NW-SE normal faults. Groundwater then prevalently flows at depth through Mesozoic carbonate-evaporite rocks. Hydrothermal fluids finally discharge at the surface in correspondence with the hydraulic barrier constituted by Oligocene-Miocene shales (Scaglia Fm.) and flyschs (Macigno Fm.) of the Tuscan Nappe. These formations, act as an impermeable cover for the regional carbonate-evaporite reservoir, and have an estimated thickness of 800 to $1000 \mathrm{~m}$ in the Bagni di Lucca area. Thermal waters prevailingly emerge in the form of artesian springs, at the contact between the Macigno sandstone and his debris cover. The debris cover hosts a perched aquifer where thermomineral waters mix with local meteoric water. The maximum water temperature registered in the area is $53.4{ }^{\circ} \mathrm{C}$ (Doccione spring at $205 \mathrm{~m}$ a.s.1.).

\section{Material and methods}

A total of 41 water samples were collected during the survey. Temperature $(\mathrm{T}), \mathrm{pH}$, electrical conductivity (EC), and alkalinity (alk) were measured directly in the field with high precision portable instrumentation $(\mathrm{T}, \mathrm{pH}, \mathrm{EC})$, and by acidimetric titration with $\mathrm{HCl}$ $0.1 \mathrm{~N}$ (alk). Samples collected for the determination of $\mathrm{Ca}, \mathrm{Mg}$, and $\mathrm{SiO}_{2}$ were filtered 
through $0.45 \mu \mathrm{m}$ membrane filters and acidified with $\mathrm{HCl}$. The following analyses were performed in CNR-IGG laboratories: $\mathrm{Cl}$ and $\mathrm{SO}_{4}$ by ion chromatography; $\mathrm{Ca}, \mathrm{Mg}, \mathrm{Na}, \mathrm{K}$, by atomic absorption spectrophotometry; $\mathrm{SiO}_{2}$ by visible spectrophotometry. $\mathrm{F}$ was analysed in CNR-ISE laboratories. A continuous automatic monitoring station was operating on Bernabò thermal spring during the period June 2003 to September 2004. Equipped with specific sensors for the simultaneous measurement of temperature, electrical conductivity, $\mathrm{pH}$ and redox potential, the monitoring station operated with flowing water (about $5 \mathrm{~L} / \mathrm{min}$ ) by recording 1 datum every 2 minutes. Data were transmitted to CNR-IGG by via GSM/GPRS modem.

\section{Hydrogeochemical results and discussion}

The chemical composition of Bagni di Lucca (BL) waters is inspected with the LangelierLudwig [6] square diagram, and related salinity section, of Figure 2. In this diagram, BL waters (green dots) are plotted along with (i) cold springs fed by superficial hydrogeological structures hosted in evaporite-carbonate rocks (yellow squares), (ii) or in limestones, arenaceous, marly-limestones, shales and siltstones interbedded with limestones and calcarenites (blue squares) [7-9]. Bernabò water samples (collected on a monthly basis during the period June 2003 to September 2004; red dots) are also shown.

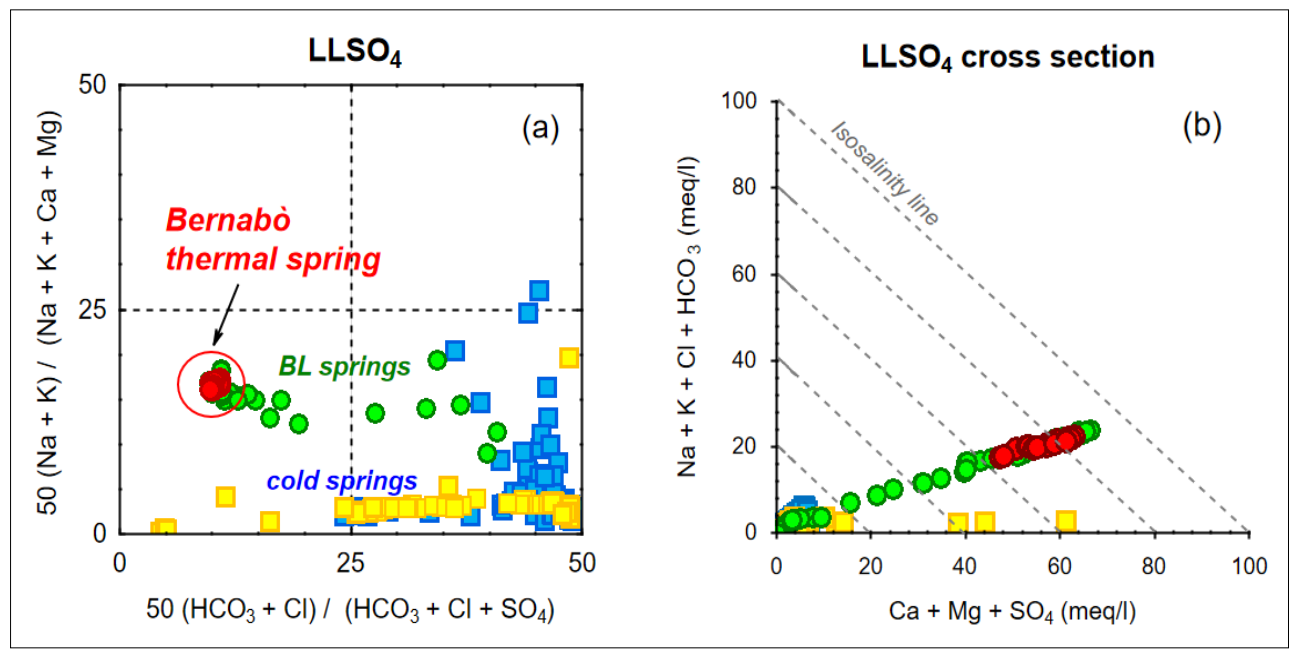

Fig. 2. $\mathrm{SO}_{4}$ Langelier-Ludwing square diagram (a), and $\mathrm{LL} \mathrm{SO}_{4}$ cross section (b), for 41 Bagni di Lucca (BL) springs (green dots), Bernabò thermal spring (red dots), and cold springs from Serchio Valley (yellow and blue squares).

It emerges that thermal, saline waters have a $\mathrm{Ca}-\mathrm{SO}_{4}$ signature, that cold, oligomineral springs have a $\mathrm{Ca}-\mathrm{HCO}_{3}$ composition, and that $\mathrm{BL}$ thermal waters are affected by different degrees of mixing with local meteoric waters. Unlike cold waters, whose mineralization process is mainly attributable to the dissolution of calcite (Fig. 3a), BL thermal waters have efficiently interacted with anhydrites (Fig. 3b) of Burano Fm. and calcareous-dolomitic breccias of Calcare Cavernoso Fm. (basal rocks of the Tuscan Nappe, both of Upper Triassic age). The $\mathrm{SO}_{4} / \mathrm{Ca}$ and $\mathrm{Na} / \mathrm{Cl}$ ratios higher than anhydrite/gypsum and halite stoichiometric dissolution lines, respectively, were interpreted as an effect of calcite deposition, and of the long-term interaction with carbonate rocks containing of albite, phyllosilicates and silica phases $[10,11]$. 

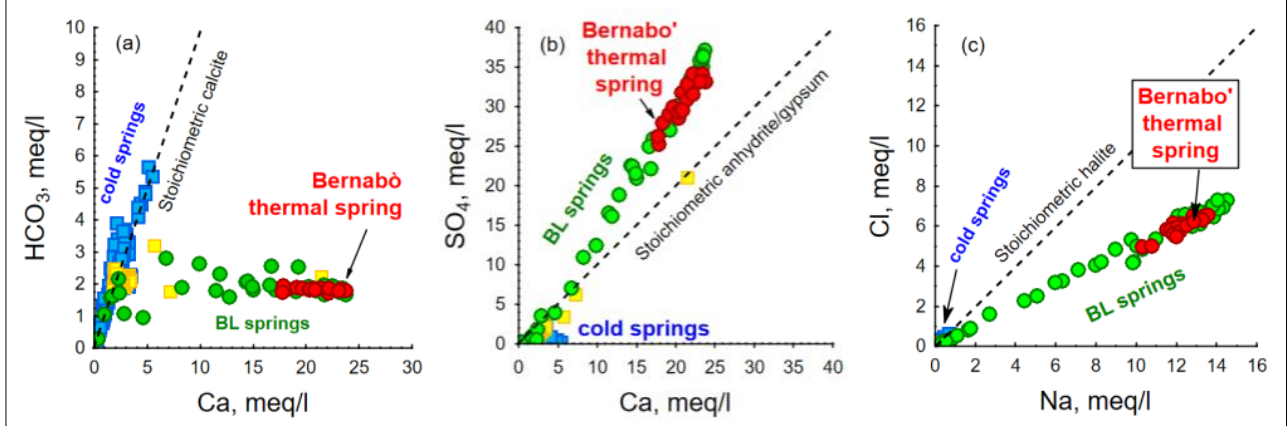

Fig. 3. Binary diagrams for $\mathrm{HCO}_{3}$ versus $\mathrm{Ca}(a), \mathrm{SO}_{4}$ versus $\mathrm{Ca}(\mathrm{b})$, and $\mathrm{Cl}$ versus $\mathrm{Na}(\mathrm{c})$.

This is in agreement with previous studies on the same area (Serchio valley, [3]), that have demonstrated that $\mathrm{Na}$ can be acquired in aqueous solution by prolonged interaction of waters with albite dispersed in siliciclastic rocks present in the local stratigraphic pile. Further to this, speciation calculations indicate that BL thermal waters are saturated with respect to fluorite, gypsum and anhydrite. By applying the $\mathrm{SO}_{4}-\mathrm{F}$ geothermometer specifically calibrated for carbonate-evaporite geothermal reservoirs [12], a theoretical chemical equilibrium temperature of $57^{\circ} \mathrm{C}$ is estimated.

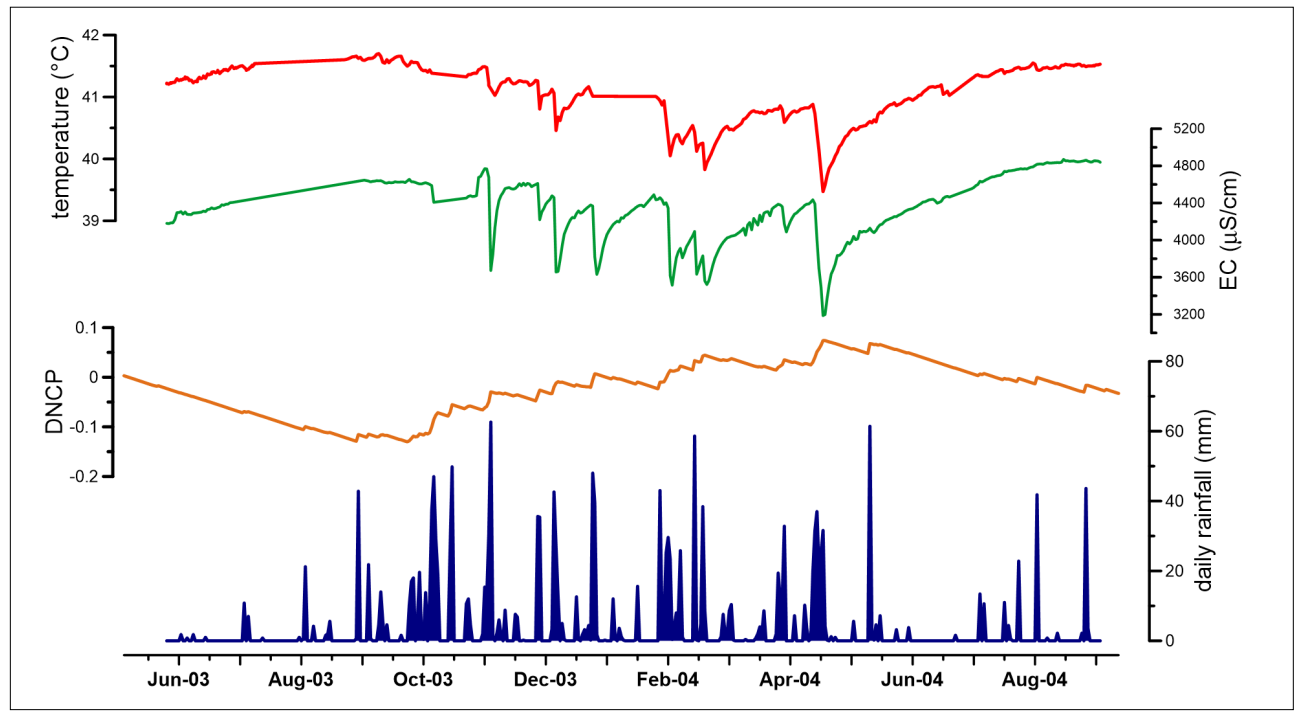

Fig. 4. Water temperature (red line) and electrical conductivity (green line) continuous record compared with DNCP (orange line) and local daily precipitations (blue bars) recorded at Borgo a Mozzano during the June 2003 to August 2004 period. The precipitation dataset was kindly provided by the Hydrological Service of the Tuscany Region (http://www.sir.toscana.it/).

The continuous signals of temperature $(\mathrm{T})$ and electrical conductivity (EC) recorded by the monitoring station of Bernabò spring (Fig. 4) are strongly correlated (correlation index: 0.9). A strong, inverse correlation (correlation index: -0.8) exists instead between these two variables ( $\mathrm{T}$ and $\mathrm{EC}$ ) and the cumulate amount of precipitation (signal processed for detrendization and normalization; DNCP).

Overall, this feature is interpreted as an indication of the fact that the natural variability of the thermal spring is attributable to mixing/dilution processes with the local low-salinity, 
shallow groundwater, directly fed by meteoric recharge. We conclude that near-surface mixing/dilution processes exclusively occur in the perched aquifer hosted in the debris cover of the Macigno sandstone. Despite these mixing processes, although limited, with shallow groundwater of meteoric origin, the Bernabò spring proves to be representative of deep-seated circuits and it ranks as a favorable site for recognizing fluids possibly connected to permeability variations induced by seismogenic processes at depth.

\section{Conclusions}

With an average discharge temperature of $\sim 41.2{ }^{\circ} \mathrm{C}$, the Bernabò spring was selected in the Bagni di Lucca area as a suitable suite to investigate hydrogeochemical precursory of seismic phenomena. Geological, hydrogeological and geochemical data were combine to sketch out a circulation model of the hydrothermal system. Main features are as follows: (i) the Mesozoic carbonate outcrops in the Lima valley are identified as the main recharge area of the hydrothermal system; (ii) thermal waters acquire a $\mathrm{Ca}-\mathrm{SO}_{4}$ signature, with high $\mathrm{Na} / \mathrm{Cl}$ ratios, after interaction with carbonate-evaporitic rocks of reservoir, and possibly siliceous rocks of Paleozoic basement and impermeable cover; (iii) thermal waters upflow along some of the most important NW-SE neo-tectonic structures of the Serchio valley, one of the areas of highest seismic risk in Tuscany, Italy and (iv) undergo limited mixing/dilution with cold, meteoric waters, just before the discharge. Thanks to these features the Bernabò spring proves to be a favorable site for recognizing fluids possibly connected to permeability variations induced at depth by preparatory phases of seismic activity. The coupled use of discrete and continuous geochemical monitoring techniques, along with geological and hydrogeological information, emerges as an efficient method for assessing site-specific suitability for the detection of geochemical seismic precursors.

\section{References}

1. R. Cioni, et al., Nat Haz Earth Sys Sci, 7, 405-416 (2007)

2. F. Gherardi, et al., Proc Earth Planet Sci, 17, 360-363 (2017)

3. F. Gherardi, L. Pierotti, Appl Geochem, 92, 166-179 (2018).

4. G. Martinelli, D. Albarello, Ann Geophys, 40, 1505-1522 (1997)

5. L. Carmignani, R. Kligfield, Tectonics, 9, 1275-1303 (1990)

6. W.F. Langelier, H.F. Ludwig, Water Works Assoc, 34, 335-350 (1942)

7. R. Drysdale, et al., Env Geol, 40, 1037-1050 (2001)

8. L. Pierotti, et al., Proc Earth Planet Sci, 7, 697-700 (2013)

9. L. Pierotti, et al., Phys Chem Earth, 83, 131-140 (2015)

10. T. Boschetti, et al., J Hydrol, 307, 270-293 (2005)

11. G. Venturelli, et al., Geochem J, 37, 351-366 (2003)

12. L. Marini, et al., Geothermics, 15, 77-86 (1986) 